\title{
Rabbit snake-bite model to assess safety and efficacy of anti viper chicken antibodies (IgY)
}

\author{
Lissy Kalliyana Krishnan ${ }^{1,}$ *, Juliet Baby Saroja ${ }^{1}$, Madhumati Rajalingam¹, Vimala John ${ }^{1}$, \\ Mohanan Parayathala Valappil ${ }^{2}$, Harikrishnan Vijayakumar Sreelatha ${ }^{3}$ \\ ${ }^{1}$ Thrombosis Research Unit, Biomedical Technology Wing, Sree Chitra Tirunal Institute for Medical Sciences and Technology, Trivandrum- \\ 695012, India \\ ${ }^{2}$ Division of Toxicology, Sree Chitra Tirunal Institute for Medical Sciences and Technology, Trivandrum-695012, India \\ ${ }^{3}$ Division Laboratory Animal Science, Biomedical Technology Wing, Sree Chitra Tirunal Institute for Medical Sciences and Technology, \\ Trivandrum, INDIA-695012
}

\section{Email address:}

lissykk@sctimst.ac.in (L. K. Krishnan)

\section{To cite this article:}

Lissy Kalliyana Krishnan, Juliet Baby Saroja, Madhumati Rajalingam, Vimala John, Mohanan Parayathala Valappil, Harikrishnan Vijayakumar Sreelatha. Rabbit Snake-Bite Model to Assess Safety and Efficacy of Anti Viper Chicken Antibodies (IgY). American Journal of Clinical and Experimental Medicine. Vol. 3, No. 1, 2015, pp. 32-38. doi: 10.11648/j.ajcem.20150301.14

\begin{abstract}
Infusion of mammalian antivenom is considered to be the best available treatment for snake bites; but, production of cost-effective IgG in pure form is challenging. Purification of egg yolk immunoglobulins (IgY) raised against various toxins has been found to be relatively easier. But to use IgY for therapeutic purpose its efficacy and safety need to be experimentally proven which is hardly done due to lack of an appropriate model. In this study, pure IgY against viper venom was isolated and its efficacy and safety for intravenous infusion was tested in rabbits. Rabbit snake bite model was created by subcutaneous injection of $2 x$ lethal dose50 (LD50) venom. Animals were given intravenous infusion of pure anti-viper IgY and recovery was monitored. Isolated chicken immunoglobulin ( $\mathrm{IgY})$ was $>90 \%$ homogenous and showed $1: 32$ titre in immunodiffusion experiment. The minimum hemorrhagic dose (MHD) of viper venom was $0.2 \mathrm{mg}$ and antihaemorragic dose (AHD) of IgY was $4 \mathrm{x}$ concentration $(0.8 \mathrm{mg})$ of native venom. Subcutaneously injected venom at LD50 resulted in severe local reaction, coagulation abnormality and mortality in rabbits. When anti viper IgY was infused within $2 \mathrm{~h}$ of envenomation, the animals survived, clotting parameters were reversed to normal and animals showed steady weight gain like healthy animals. No adverse effect of IgY was noticed on renal or hepatic function. The efficacy of commercially available mammalian IgG was lower than that of anti-viper IgY. Long term stability of the purified and lyophilized IgY was demonstrated. The effective IgY dose required to prevent mortality in the envenomed rabbits was found to be $4 \mathrm{x}$ of the injected venom estimated by Lowry's protein assay. It has been demonstrated that rabbit model of snake bite is successfully cured by anti-snake IgY infusion at a specific dose.
\end{abstract}

Keywords: Antivenom, Chicken IgY, Russell's Viper, Effective Dose, Animal Model

\section{Introduction}

Snake bite associated morbidity and mortality is a major public health problem in many of the tropical countries. Intravenous infusion of anti venom is the best treatment option for snake bite envenomation ${ }^{1}$. Development of mammalian anti venom immunoglobulin (IgG) in equine has been the accepted antivenom production method in many laboratories which need to conform to pharmacopoeia regulations ${ }^{2}$. Since the process of anti venom purification from equine serum is laborious and expensive, fewer efforts are taken to produce antibodies in pure form. In many of the commercially available products, IgG is a minor fraction; the specific antibody against each toxin is likely to be much lower ${ }^{3}$. Purer the antivenom, the higher will be the cost of production. So, cost effective method for development of pure antibodies needs more attention.

Avian antibodies (IgY) have been raised against different toxins and hen is considered to be a better host for large scale production of antibodies ${ }^{4,5}$. The IgY has better stability as compared to mammalian IgG and has better antigen binding efficiency. Antigen-induced immunoglobulins that are 
developed in hens get concentrated in the egg yolk. There is less number of proteins in yolk as compared to mammalian serum, but lipid content is very high. Purification of IgY from lipid-free yolk diluted in water is found to be easier ${ }^{6}$. However, if lipid is not removed efficiently, protein-lipid micelle compromises the purity. In this study, we have modified our previous method ${ }^{6}$ to improve the purity of $\operatorname{IgY}$ and demonstrated a better in vitro reactivity of $\operatorname{IgY}$ with venom.

An important problem that is faced world-wide is in testing the potency of antibody in suitable model to calculate the human dose required ${ }^{7}$. So a model mimicking snake bite was proposed to be versatile in identifying the efficacy and safety of intravenous IgY infusion. We demonstrate use of rabbit snake bite model to estimate the effective dose (ED50) which may be appropriate for testing different antibody preparations.

\section{Materials and Methods}

Venom was collected from a local government serpantarium after required regulatory clearance. Russell's viper venom was milked into $\sim 10 \mathrm{x}$ volume of normal saline. The venom milked from 3 animals were pooled, aliquot of $0.5 \mathrm{ml}$ volume was stored at $-80^{\circ} \mathrm{C}$ till the use. Other reagents used for purification of $\mathrm{IgY}$ were ammonium sulphate, sodium deoxycholate [SDC] (Sigma Chemicals USA) and Sephacryl 100 (GE Healthcare, USA). For immunodiffusion, molecular biology grade agarose (Sigma Chemicals, USA) was used.

Institutional Animal Ethics Committee (IAEC) approval which conforms to CPCSEA (Govt of India) regulations was obtained for using hens to raise antibodies. To the pectoral muscle of White Leghorn hens, sub lethal concentration of venom (Lowry's protein assayed) mixed with complete adjuvant (Sigma Chemicals, USA) was injected to immunize the bird. The eggs obtained 12 days after primary immunization was processed and collected the yolk. On the $35^{\text {th }}$ day and $70^{\text {th }}$ day, booster dose of venom mixed with incomplete adjuvant was given. Eggs were collected till $90^{\text {th }}$ day after the primary immunization.

Egg yolk was separated from albumin and before breaking the sac, the yolk was washed thoroughly with plenty of distilled water. The sac was punctured to collect the yolk and was diluted with $3 \mathrm{x}$ double distilled water. The diluted yolk was frozen for $>24 \mathrm{~h}$ at $-80^{\circ} \mathrm{C}$ and thawed slowly at $4^{\circ} \mathrm{C}$ to precipitate the lipid. The suspension was centrifuged at $22,000 \mathrm{~g}$ in a high speed centrifuge (Hitachi SCR55, Japan). The supernatant was collected carefully, and proteins were precipitated with $70 \%\left(\mathrm{NH}_{4}\right)_{2} \mathrm{SO}_{4}$. Precipitate was collected by centrifugation at $10,000 \mathrm{~g}$ and dissolved in $50 \mathrm{mM}$ PBS; 5 $\mathrm{ml}$ aliquots were stored at $4^{\circ} \mathrm{C}$. The $\left(\mathrm{NH}_{4}\right)_{2} \mathrm{SO}_{4}$ precipitated protein was mixed with $0.2 \% \mathrm{v} / \mathrm{w}$ SDC and was incubated for $1 \mathrm{~h}$. Further purification was done by gel filtration using Sephacryl column connected to protein purification system (AKTA Prime GE Health, USA). The eluted first peak- and second peak- fractions were separately pooled and used for analysis of purity. An alternate purification method adopted was affinity chromatography using 2-mercaptopyridine coupled Sepharose (GE Healthcare, USA) according to the protocol provided by the manufacturer. Before loading the protein on to the affinity chromatography column, the $\left(\mathrm{NH}_{4}\right)_{2} \mathrm{SO}_{4}$ precipitated protein was dialyzed against the binding buffer. Column $(1 \mathrm{ml})$ was equilibrated, the protein solution was loaded, washed and the bound protein was eluted as per the protocol provided by the manufacturer, using AKTA Prime protein purification system.

At various stages of purification, protein was assayed using Lowry's method for calculating the recovery and yield. To test for purity, SDS-PAGE electrophoresis was performed on $8 \%$ gel and the bands were developed with Coomassie Brilliant Blue. For the immunodiffusion, $0.8 \%$ agarose was melted in barbitone buffer ( $\mathrm{pH} 7.4$ ), and the gel was cast on microscope slides. Using a standard immunodiffusion template, wells were cut, known concentrations of serially diluted IgY was added into the peripheral wells and known concentration of venom was added in the middle well. The slide was incubated for $72 \mathrm{~h}-96 \mathrm{~h}$ at $4^{\circ} \mathrm{C}$ in a humidified airtight chamber. Once the precipitin line was visible, the slide was immersed in plenty of saline for $24 \mathrm{~h}$ to remove unreacted proteins. The gel was dried by inverting over several layers of filter paper and dried slides were stained with Commassie Brilliant Blue.

The test for abnormal toxicity was done as per CFR Sec. 610.11 General Safety. The pure IgY was injected (intra peritoneal) to two mice weighing $<22 \mathrm{~g}$ and 2 Guinea pig weighing $<400 \mathrm{~g}$. In both species, animals were observed for 7 days. Each test animal was weighed and the individual weights were recorded just prior to injecting IgY. Animal weight was monitored for 7 days. Criteria for passing the test were: all animals survive and weigh no less at the end of the test period than at the time of injection.

Adult New Zealand white rabbits weighing $>2.5 \mathrm{~kg}$ were used for testing the efficacy. Blood was collected on the previous day of experiment and 7/15 days after the experiment for biochemical and hematological analysis. For assay of minimum hemorrhagic dose (MHD) and anti hemorrhagic dose (AHD) as described in the WHO workshop (Theakson 2003), the back of the animal was clipped and shaved. Four to five points were marked on each lateral side and $10 \mathrm{~mm}$ diameter circle around the point was marked. Graded concentrations of venom were injected subcutaneously at each marked point. The hemorrhage was measured and graded after $30 \mathrm{~min}$. The minimum dose at which hemorrhage of $10 \mathrm{~mm}$ diameter was measured in 30 min is defined as MHD. For anti hemorrhagic assay, MHD concentration of venom was premixed with increasing concentration of IgY, incubated for $30 \mathrm{~min}$ at $37^{\circ} \mathrm{C}$ and were injected at different points marked at the back.

For creating in vivo snake bite model, animal (rabbit) back was shaved and the venom $(1 \mathrm{mg} / \mathrm{kg})$ was injected. Between $2 \mathrm{~h}$ to $6 \mathrm{~h}$ after injecting venom, $4 \mathrm{x}$ venom concentrations (4 $\mathrm{mg} / \mathrm{kg}$ body weight) of IgY (test) or IgG (control) was mixed into $15 \mathrm{ml}$ sterile saline and was infused through the 
marginal ear vein. Animals were put back into the cage and monitored. Biochemical parameters were assayed using commercially available standard kits and semi automated chemistry analyzer (ERBA Chem-7, Transasia, India), complete blood count (CBC) was taken using automated analyzer (ABX vet model, France) and coagulation parameters were measured using standard reagents from Diagnostica Stago (France) on a Coagulation Analyzer (Stago Start4, France). All laboratory tests are under quality system as per ISO17025 and are accredited by COFAC (France).

\section{Results}

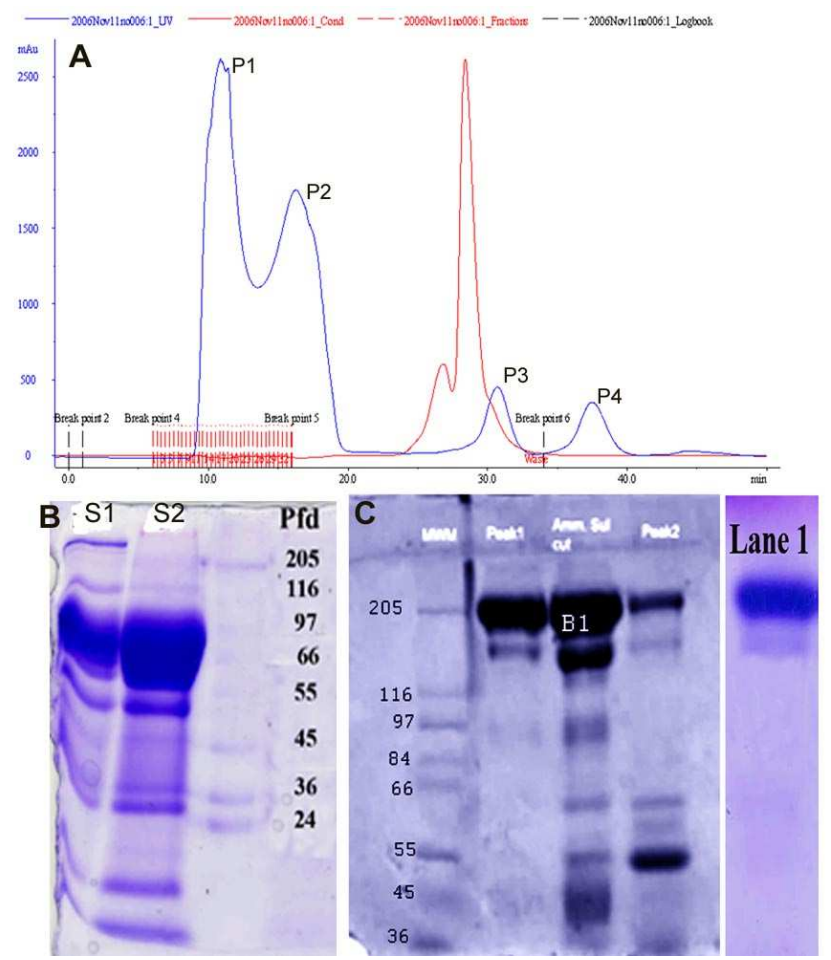

Fig. 1. Results of purification and analysis of $\operatorname{IgY}$. A, Pattern of chromatographic elution of proteins peaks; B, SDS-PAGE pattern of commercial IgG; C, SDS-PAGE pattern of crude and pure IgY. The tracing in the chromatogram is absorbance of protein eluting, the red tracing indicates conductivity. One $\mathrm{ml}$ fractions were collected; $1^{\text {st }} \& 2^{\text {nd }}$ peak were pooled separately, Lowry's protein was detected and used for analysis. IgG from two sources were analyzed and both are shown. Lanel marked in $C$ is $\mathrm{IgY}$ purified by affinity chromatography; $\mathrm{NH}_{2}\left(\mathrm{SO}_{4}\right)$ precipitate, peak1, peak2 that were eluted from gel filtration column and $M W$ marker lanes are marked in the figure.

A method for purification of IgY, using gel filtration chromatography was described in previous publication ${ }^{6}$. The modified purification protocol described in this study demonstrated efficient separation of proteins into two major and two minor peaks during chromatography (Fig.1A). Upon SDS-PAGE analysis, separation of $\operatorname{IgY}$ into pure form in the first eluted peak was evident. The crude $\left(\mathrm{NH}_{4}\right)_{2} \mathrm{SO}_{4}$ precipitated fraction showed several bands ranging from $\sim 200 \mathrm{kDa}$ to $40 \mathrm{kDa}$ molecular weight. The MW of the IgY was confirmed using affinity purified protein, to be 180 to
$200 \mathrm{kDa}$ (Fig 1C). The protein that eluted in the first peak from gel filtration column also showed mainly the $\operatorname{IgY}$ band at $\sim 200 \mathrm{kDa} \mathrm{MW}$ and a second minor band, very close to it which was not separated by either gel filtration or affinity chromatography. Protein that eluted as the second peak of the chromatogram had $\operatorname{IgY}$ band but at lower intensity and other bands corresponding to lower molecular weights were visible. Two sources of commercially available anti venoms were analyzed. In both products, IgG band $(150 \mathrm{kDa})$ was hardly prominent but the albumin band $(66 \mathrm{kDa})$ was the most visible one (Fig 1B). It appears that only $<5 \%$ of the total protein is $\mathrm{IgG}$ in both cases. Therefore, purity of commercially available anti venom is considerably low.

Immuno diffusion experiment showed that the titre of $\operatorname{IgY}$ was 1:4 after the first immunization (Fig 2A), and titre was $>$ 1:32 (Fig 2B) when eggs were processed and IgY purified after giving booster. The result indicates that in a unit concentration of IgY, the specific immunoglobulin against venom toxins increased when the booster was given. In both commercial preparations, titre was $\sim 1: 2$ (Fig 2 C\&D). The major difference in the case of commercial preparation was that they formed bands at different positions and multiple bands were formed near the wells. In the case of IgY the precipitin line was formed as thick band which suggests that antibody was developed against each antigen with similar response and precipitin lines were formed at an equidistant position between antigen and antibody wells.

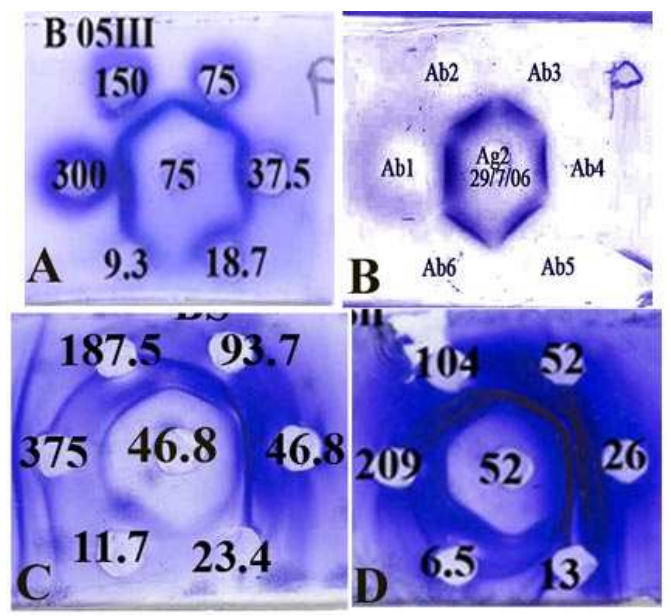

Fig. 2. Ouchterlony's immunodiffusion. A\& B, Immunodiffusion of purified $\operatorname{IgY}$ after $1^{\text {st }}$ booster and $2^{\text {nd }}$ booster. $C \& D$, Immunodiffusion of IgG from two different sources. Dilution of $\operatorname{Ig} Y$ was done and in $B, A b 1(1)$ is the highest concentration and Ab6(1:32) is the lowest.

Abnormal toxicity test was passed favorably because all animals gained weight, similar to their litter group. For detection of minimum haemorrhagic dose (MHD), 5 different concentrations of venom were injected such as $0.15 \mathrm{mg}, 0.20 \mathrm{mg}, 0.25 \mathrm{mg}$ or $0.30 \mathrm{mg}$ per site. Dose $3(0.25$ $\mathrm{mg}$ ) created hemorrhage of $10 \mathrm{~mm}$ dia in $30 \mathrm{~min}$ after injection (Fig 3A). Four sites were used for each dose using replicate animals and the results were found repeatable. For MHD, dose 1 and dose 2 were not hemorrhagic. So, for detection of anti hemorrhagic dose (AHD), dose 3 (0.25 mg 
venom) was mixed with 4 different concentrations of anti venom such as $1 \mathrm{x}(0.25 \mathrm{mg}), 2 \mathrm{x}(0.5 \mathrm{mg}), 3 \mathrm{x}(0.75 \mathrm{mg}), 4 \mathrm{x}(1$ $\mathrm{mg}$ ), mixture was incubated at $37^{\circ} \mathrm{C}$ and injected at four points for each composition; one on the left and the other on the right, in 2 such animals as shown in Fig 3B. One site was injected with $4 \mathrm{x}(1 \mathrm{mg})$ dose of $\operatorname{IgY}$ alone. Hemorrhagic area was measured to identify the effectiveness of anti venom to reverse the hemorrhagic effect of $0.25 \mathrm{mg}$ venom. When IgY was used to neutralize the venom, hemorrhage was the lowest at $4 \mathrm{x}$ IgY concentration, when mixed with venom $(0.25 \mathrm{mg}$ venom $+1 \mathrm{mg} \operatorname{IgY})$. Injection of $\mathrm{IgY}$ alone did not cause any hemorrhage or edema. Replicate experiments were carried out to confirm the observation; separate animals were used to test commercial IgG from each source.

For creation of snake bite model, subcutaneous injection of venom was given. One $\mathrm{mg}$ venom per $\mathrm{kg}$ body weight was selected because during MHD experiment, total venom injected to all 8 sites together was $2 \mathrm{mg}$ for the animal weighing $>2 \mathrm{~kg}$ making the total injected dose $1 \mathrm{mg} \mathrm{kg}^{-1}$. At this dose, animals were very sick and more than $50 \%$ died within $48 \mathrm{~h}$. The observation indicated that $1 \mathrm{mg} \mathrm{kg}^{-1}$ can be lethal to rabbits. When $1 \mathrm{mg} \mathrm{kg}^{-1}$ venom was used as controls ('no anti venom' group), out of three animals, 2 died within $24 \mathrm{~h}$. So it is confirmed that $1 \mathrm{mg} \mathrm{kg}^{-1}$ is lethal to rabbits. In all animals in the experimental groups, a severe hematoma was found at the site of injection within $30 \mathrm{~min}$ after injection (Fig4A). Four times $(4 \mathrm{x})$ concentration of IgY was given intravenously (Fig.4 B \& C). The logic for using this dose of IgY was that in the AHD experiment, venom mixed with $4 x I g Y$ showed very minimal hemorrhage (Fig 3B). This dose was effective and all animals survived. Reversal of hematology parameters to normal level was also achieved within a week. Even though there was severe reaction on the second day of the experiment (Fig 5 A), by two weeks the wound healed and there was normal appearance around the wound (Fig $5 \mathrm{C} \& \mathrm{D}$ ). Also when the venom dose was increased to $2 \mathrm{mg} \mathrm{kg}^{-1}$ body weight, all animal survived if anti venom dose was also increased proportionately to achieve $4 \mathrm{x}$ the dose of venom; i.e. increasing the $\operatorname{IgY}$ dose to $8 \mathrm{mg} \mathrm{kg}^{-1}$ body weight. This time, three animals out of four survived after the infusion of IgY. One animal died in $48 \mathrm{~h}$, probably because IgY infusion could not be completed due to severe hematoma at the site of infusion (Fig 5B).

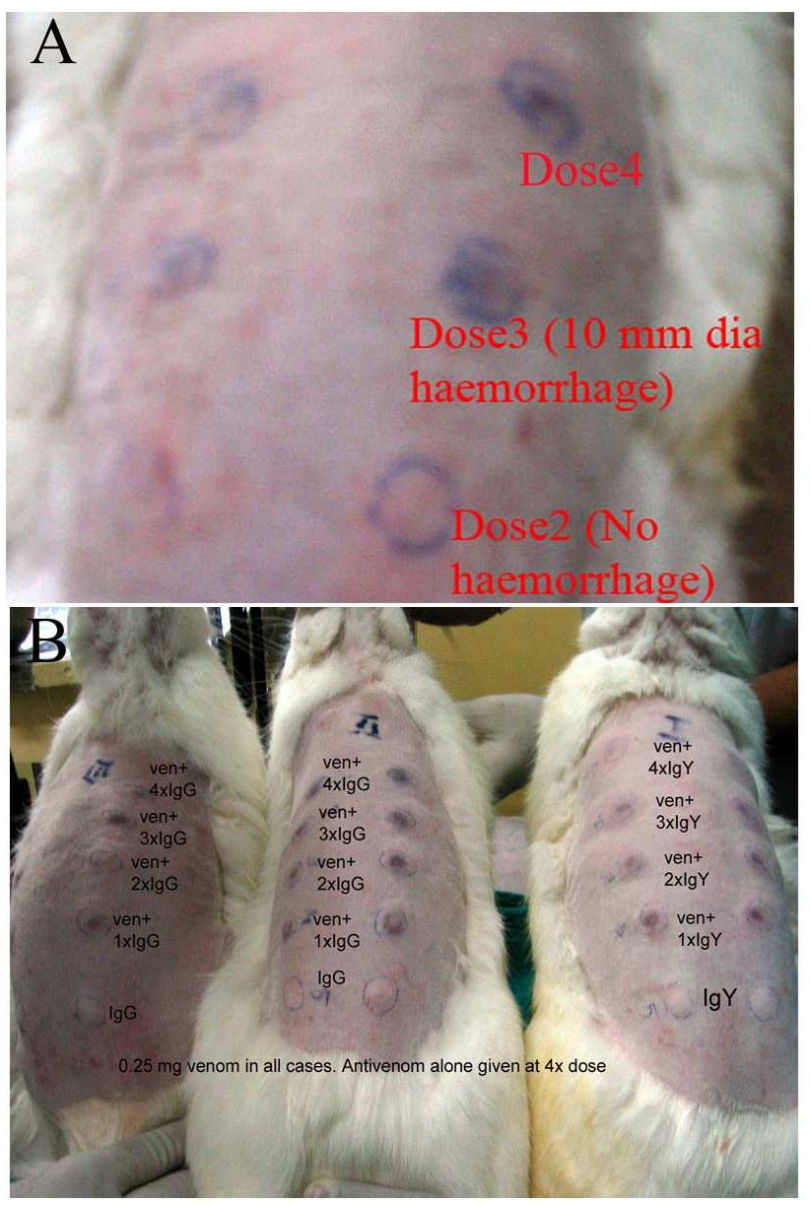

Fig. 3. Image of injections sites of $M H D \& A H D$ detection A, Sites of hemorrhage $30 \mathrm{~min}$ after injection of venom; $B$, Sites of hemorrhage $30 \mathrm{~min}$ after injection of venom-IgY or venom $\operatorname{Ig} G$ mixtures. The composition injected on left and right sides are similar and are marked in the figure.

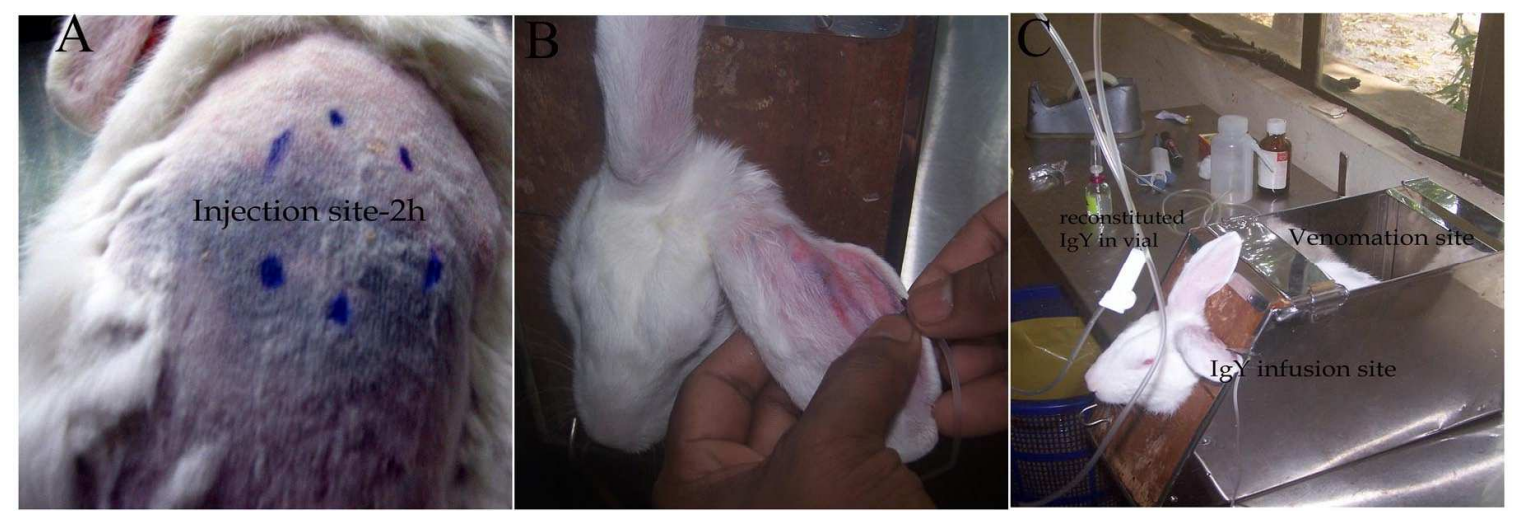

Fig. 4. Representative images of the experiment. A, injection site: $B$, infusion in progress: $C$, Set up for infusion. Severe hemorrhage was observed $2 h$ after subcutaneous injection of venom. Smooth infusion of IgY was done through the marginal ear vein. 

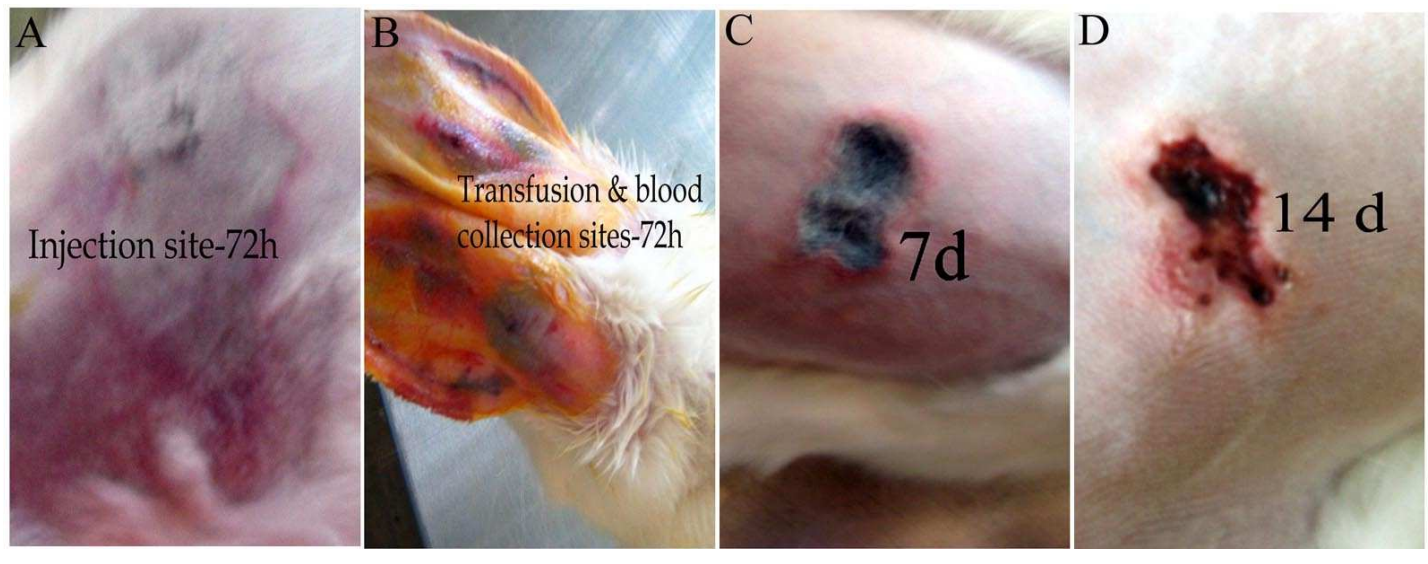

Fig. 5. Representative images showing recovery. A, venom injection site after $72 h ; B$, infusion site after $72: C$, injection site after 7 d and $D$, injection site after $2 \mathrm{wks}$. Hemorrhage on the ear after $72 \mathrm{~h}$ is due to the attempt to collect blood for analysis. Severe hemorrhage is seen; so blood could be collected only on the $7^{\text {th }}$ day.

The blood tests that were done include, complete blood count, plasma $\mathrm{Hb}$, prothrombin time (PT), activated partial thromboplastin time ((APTT), clottable fibrinogen, urea, creatinine, serum alanine transaminase (ALT/SGPT), total protein and albumin. In animals that were infused with $\operatorname{IgY}$ after envenomation, all parameters including APTT were normal by 7 days, except an initial high level of fibrinogen and low platelet count which was reversed back to normal within 14 days of the experiment. The increase in fibrinogen may be attributed to the inflammation. When $\operatorname{IgY}$ was administered without any venom dose, all parameters remained in the same range as the basal level, at all periods of measurement. In the control (commercial IgG) group, only one out of three animals survived with similar dose as IgY. In the survived animal, APTT was very high after $7 \mathrm{~d}(>500 \mathrm{~s})$, fibrinogen level was high till 2 weeks and platelet count was $50 \%$ of the basal level (count before envenomation). So overall, it was suggestive of poor reversal of hemostasis if IgG was used, whereas $100 \%$ recovery on infusing $4 \mathrm{x}$ IgY was observed. After IgY infusion at both dose $(4 \mathrm{mg} / \mathrm{kg}$ or $8 \mathrm{mg} / \mathrm{kg}$ body weight) the renal function and liver function remained steady as confirmed by routine biochemical tests.

\section{Discussion}

Anti venom therapy is currently indispensable in cases of snake bite envenomation as there is no alternate effective treatment. There are many different species of venomous snakes and there is geographical distinction in their frequency. So, commercialization of a universal preparation that can be effective and pure is far from reality. It is the geographical diversity in the type of venom which makes it difficult to focus on the availability of uniformly pure preparations of anti venom for all snakes. In India and other Asian countries there are 4 major types of venomous snakes and anti venom against all the 4 type together are available commercially and are used for any snake bite. The major problem with these preparations is that majority of them are available in a less pure state. The purification of IgG from mammalian serum is laborious and the purified product may become more expensive. So to compromise the cost and wide availability, poly specific antibodies in less pure form are being sold. Less pure forms will have less specific antibodies which pose a need for increase in quantity infused. When we analyzed two commercial sources of antibodies, more or less similar protein profile was found in both. In SDS-PAGE, only very minor band is seen in $150 \mathrm{kDa}$ region which correspond to IgG. Upon infusion, the preparation heavily contaminated with other proteins can lead to problems such as serum sickness. So, to solve these side reactions, it is important to develop antibodies in pure form according to the guideline from $\mathrm{WHO}^{8}$.

The efficacy and safety profiles of most of the anti venoms that are routinely used in South Asia have not been well established. Up to $80 \%$ of patients treated with such anti venoms present one or more adverse effect(s) such as anaphylactic or pyrogenic reactions, or late serum sickness $^{9,10}$. The risk of severe adverse events must be balanced against the life-saving potential of this treatment. When it is difficult to estimate how much immunoglobulin is present in the preparation, dose calculations become practically impossible. Our major goal was development of pure anti venom that is tested appropriately to give a clear indication to its safety, efficacy and dosage. Our current focus is on Russell's viper venom antibodies; mainly because it is possible to monitor coagulation parameters which indicate the extent of toxic effects of envenomation and possible normalization upon anti venom infusion. Among the true vipers, Russell's viper (Daboia russelii) is associated with the highest morbidity and mortality. In south Asia, starting from Sri Lanka to foot hills of Himalayas including Nepal, Bangladesh and Pakistan this species is a major cause for snake bite deaths ${ }^{11}$.

In recent years it is understood that hen is a good host for producing antibodies. Affinity chromatography is one of the best techniques to obtain the purest protein. In our effort for purification of IgY by affinity chromatography, the yield was relatively very low on affinity purification and insufficient quantity for therapeutic use was obtained. Low yield may be due to poor binding efficiency of the ligand to the column 
material. Both gel filtration and affinity chromatography resulted in similar level of purity in our experiment. The first peak in our earlier study was not well resolved and proteins of many sizes eluted together, which could be due to micelle formation $^{6}$. The lipid content in the extract increases the chance for micelle formation. Significant outcome was observed when detergent was used to break micelles. This study demonstrates resolution of proteins into two distinct major peaks, out of which the first one showed good purity and yield. Up to $20 \mathrm{mg}$ pure IgY could be obtained from one egg. This method of salt precipitation followed by gel filtration in presence of SDC produced active antibody that showed good titre in Ouchterlony's immuno diffusion experiment.

Once we found that the titre, purity and recovery were improved, the next objective was to identify the effective dose. The AHD which was estimated as per the CPMP protocol showed that 1:4 composition of venom:IgY is sufficient to reduce the hemorrhage when the pre-incubated mixture of venom and antivenom was injected. Out of the two commercially obtained anti venoms, one was effective for reducing the hemorrhage but the other was not. For the efficacy evaluation similar composition was infused in the rabbit model of snake bite.

To create the model, animals were injected with venom which resulted in severe reaction at the site of injection and lethality if no anti venom was infused. On infusion of the IgY, all animals survived whereas with commercial IgG infusion only $33 \%$ survival was achieved. The animal which survived was very sick and took long duration to recover from the signs of toxicity. Only a single dose of IgY or IgG could be given due to the haemorrhage at the infusion site, which is a symptom of envenomation. Probably that was the major limitation in this animal model. It may be possible to give multiple dose in human subjects. Similarly, it was difficult to monitor haematology parameter after $24 \mathrm{~h}$ of subcutaneous injection of venom. So, blood was collected only 7 days after the experiment. We found this a good model to estimate the efficacy dose for treating envenomed victims. It has been estimated and published in literature that during one normal bite by Russell's viper, up to $60 \mathrm{mg}$ venom is injected; so according to the severity of reaction after the bite, the anti venom requirement may be calculated.

The dose of anti venom to be given to the patient is currently not been standardized for IgG. Therefore, many units are given to patients, which could lead to various side effects. So, two major factors that need to be considered before a new anti venom preparation is used clinically are the dose and safety. On the safety point of view, we observed there was no toxic reaction when one human dose was injected intra peritoneal to mice and guinea pigs. In addition, the rabbits maintained stable liver function and kidney function after intra venous infusion of $\mathrm{IgY}$. In $\operatorname{IgG}$ infused rabbit, even at $4 \mathrm{mg} / \mathrm{kg}$ body weight, no adverse reaction was found. It has been reported that when multiple dose of IgG is used in human there is renal failure which leads to hemodialysis. Any how if IgY is used, higher dose may not be required because at the dose administered, it was effective to reverse the toxic effect of venom. But IgG was not sufficient, so additional dose may be required.

\section{Conclusion}

Pure IgY against Russell's viper venom was produced using low dose of native venom as the antigen. Good separation of the IgY from other yolk proteins was achieved by gel filtration in the presence of detergent. The anti venom showed good antigen binding in vitro in immuno-diffusion experiments. Using rabbit model, minimum haemorrhagic dose of venom and anti haemorrhagic dose of IgY was determined. Using a newly developed preclinical model in rabbits, effective dose was estimated. The AHD and effective dose for reversing the toxic effects of subcutaneous envenomation was similar i.e. $4 \mathrm{x}$ concentration of venom dose. Infusion of $\operatorname{IgY}$ through intravenous route is found to be safe because no adverse hematological or biochemical effect was noted in the animal with and without envenomation. It is concluded that IgY produced in an almost pure form is safe and efficient for treating snake bite rabbit models which needs to be tested in limited clinical trials for patient use.

\section{Acknowledgments}

The authors acknowledge The Director, SCTIMST and The Head, BMT Wing, SCTIMST for the facilities provided. We acknowledge the support from all colleagues of Thrombosis Research Unit, Toxicology division and Laboratory for Animal Science. We would like to acknowledge funding support from Kerala State Council for Science, Technology and Environment (KSCSTE), for the financial support. The faculty and staff of Serpantarium of Ayurveda Medical College Research Centre under Govt. of Kerala, India is appreciated for milking venom from Russell's viper for the study.

Ethics: Institutional Animal Ethics Committee (IAECSCTIMST) approval was obtained for conducting animal experiments (development of antivenom in hens and rabbit animal model of snake bite) which conforms to CPCSEA regulations of Government of India.

Permission was obtained from the Department of Forest and Department of Narcotics, Government of Kerala, India for milking venom from Russell's viper for research purposes

\section{References}

[1] Chippaux JP. Snake-bites: appraisal of the global situation. Bull World Health Org. 1998; 76:515.

[2] Gutiérrez JM, Lomonte B, Leon G, Rucavado A, Chaves F, et al. Trends in snakebite envenomation therapy: scientific, technological and public health considerations. Curr Pharm Des 2007; 13: 2935. 
[3] Maya DC, Mary VB, Lal AV, Umashankar, PR and Krishnan LK.An Improved Method for Isolation of Anti- Viper Venom Antibodies from Chicken Egg Yolk . Journal of Biochemical and Biophysical Methods. 2001;51:129.

[4] Paul K, Manjula ., Deepa EP, Selvanayagam ZE, Ganesh KA and Subba Rao PV. Anti-Echis carinatus venom antibodies from chicken egg yolk: isolation, purification and neutralization efficacy. Toxicon. 2007;50: 893.

[5] Almeida CMC, Da Silva CL, Couto HP, Escocard Rde C, DA, ROCHA DG, Sentinelli Lde P, Kipnis TL, da Silva WD. Development of process to produce polyvalent IgY antibodies anti-African snake venom. 2008; Toxicon. 52:293.

[6] Maya DC, Mary VB, Krishnan LK. Development of anti viper venom antibodies in chicken egg yolk and assay of its antigen binding capacity. Toxicon, 2001;40: 857.

[7] Simpson ID. The "worldwide shortage" of antisnake venom: is the only right answer "produce more" or is it also "use it smarter?". Wilderness Environ Med 2008;19: 99.
[8] Theakston RDG, Warrell DA and Griffiths E. Erratum to report of WHO workshop on the standardization and control on antivenoms. Toxicon. 2003;41:541

[9] Seneviratne SL, Opanayaka CJ, Ratnayake NS, Kumara KE, Sugathadasa AM, et al. Use of antivenom serum in snake bite: a prospective study of hospital practice in the Gampaha district. Ceylon Med J. 2000;45:65.

[10] Premawardhena AP, de Silva CE, Fonseka MM, Gunatilake $\mathrm{SB}$, de Silva HJ. Low dose subcutaneous adrenaline to prevent acute adverse reactions to antivenom serum in people bitten by snakes: randomised, placebo controlled trial. BMJ. 1999;318:1041.

[11] Phillips RE, Theakston RD, Warrell DA, Galigedara Y, Abeysekera DT, et al.. Paralysis, rhabdomyolysis and haemolysis caused by bites of Russell's viper (Vipera russelli pulchella) in Sri Lanka: failure of Indian (Haffkine) antivenom. Q J Med. 1988;68:691. 